\title{
Contribuição do Objeto Digital de Aprendizagem "Futsal RIVED” no Processo de Ensino-aprendizagem de Educação Física
}

\author{
Contribution of Digital Learning Object "Futsal RIVED" in de Processo of Teaching and Physical Education
}

\author{
Ana Paola Bavaresco ', Liziany Muller ${ }^{2}$ e Aline Pereira de Arruda Rech ${ }^{3}$ \\ 1,2,3 Universidade Federal de Santa Maria, Santa Maria
}

\section{Resumo}

Este trabalho tem o objetivo de avaliar a contribuição de um objeto digital de aprendizagem (ODA) no processo de ensino-aprendizagem de alunos na disciplina de Educação Física. A Metodologia utilizada foi de cunho qualitativo com pesquisa-ação. O ODA usado foi o "Futsal RIVED" que apresenta uma proposta pedagógica para o ensino dos fundamentos do futsal. Realizou-se a interatividade e exploração do ODA individualmente e em grupo onde este foi analisado, discutido, explorado de acordo com os objetivos propostos pelo mesmo. Conclui-se que as tecnologias aplicadas na educação como recursos pedagógicos adquirem função de auxiliar, motivar e facilitar o processo ensino-aprendizagem trazendo novos olhares e maneiras diferentes de aprender.

Palavras-chave: TIC- Educação- Objeto Digital de Aprendizagem-Educação Física

\begin{abstract}
This study aims to evaluate the contribution of a digital learning object (ODA) in the teaching and learning process of students of Physical Education. The methodology used was a qualitative research with action. The ODA used was "Futsal RIVED" which presents a pedagogical proposal for teaching the fundaments of soccer. It was held the interactivity and exploration of ODA individually and in groups where it was analyzed, discussed, explored according to the proposed goals. It is concluded that the technologies applied in education as teaching resources acquire functions to help in the teaching-learning process bringing new views and different ways of learning.
\end{abstract}

Keywords: ICT-Education- Digital Learning Object-Physical Education 


\section{INTRODUÇÃO}

A disseminação da tecnologia permitiu que o acesso à informação se tornasse muito mais rápido e fácil, e, como não poderia ser diferente, o meio acadêmico também foi atingido, o giz, o quadro negro, o caderno e os livros já não são mais as únicas ferramentas utilizadas em sala de aula (ALMEIDA; PRADO, 2009). Com o avanço crescente das tecnologias nas últimas décadas os paradigmas da educação tradicional baseados na educação compulsória e massiva pautada nos pares transmissão-recepção, sequencia-linearidade, entregue-recebido, característicos da educação bancária necessitam ser re-significados (FREIRE, 2006).

As atuais tecnologias de informação e comunicação (TIC) apresentam novas possibilidades para o indivíduo vivenciar processos criativos, estabelecendo aproximações e associações inesperadas, unindo significados anteriormente desconexos e ampliando a capacidade de interlocução por meio das diferentes linguagens que tais recursos propiciam (MARTINSI, 2008). Conforme Kenski (1996), não se educa em um mundo que está em mudança, se não forem consideradas as tecnologias, pois, as novas gerações têm relacionamento totalmente favorável e adaptativo às TIC e um posicionamento cada vez mais aversivo às formas tradicionais de ensino.

Entre os recursos das TIC, os objetos digitais de aprendizagem (ODA) são um instrumento capaz de aumentar o interesse e atrair a atenção dos alunos pelos conteúdos, potencializando e facilitando o processo de ensino-aprendizagem. Os ODA integram de maneira lúdica, colaborativa, instigante, investigativa e motivadora, pautados pelos recursos da hipermídia visual e auditiva (imagens e efeitos de sons), às atividades pedagógicas fundamentais aos alunos construírem seu conhecimento.

Freire (2001) acredita na educação que considere o estudante construtor do seu conhecimento ao invés de somente reproduzi-los ou memorizá-los, pois ensinar não pode ser uma questão de transferência de saberes.

Contudo, ressalta-se que a utilização de ODA deve estar inserida em um ambiente de aprendizagem desafiadora, pois, Barros (2009) afirma que a tecnologia não é por si só um elemento motivador se a proposta de trabalho não for interessante, pois os alunos rapidamente perdem a motivação.

Audino e Nascimento (2010) afirmam que os ODA são recursos digitais dinâmicos, interativos e reutilizáveis em diferentes ambientes de aprendizagem, permitindo dar suporte, auxilio e incentivo ao aprendizado dos alunos.

O uso dos ODA possui várias situações positivas entre elas: uma gama de ferramentas disponíveis nos softwares, os alunos além de ficarem mais motivados tornam-se mais criativos e curiosos, e adiciona-se que alunos com dificuldade de concentração tornam-se mais concentrados (TAJRA, 2001). Guilherme et al. (2005) afirmam que objeto digital de aprendizagem é uma tecnologia recente que abre caminhos para a educação formal e a distância, podendo ser fortemente utilizada como material de apoio ao ensino presencial tradicional, trazendo inovações e soluções que podem beneficiar a todos os envolvidos nesse processo.

As aulas de Educação Física são bem aceitas sempre que existir a prática, mas no momento da teoria são consideradas aulas desinteressantes e monótonas (SEBRIAM 2009, p.24). Nesse sentido, acredita-se que o uso de ODA na disciplina de educação física pode ser uma alternativa diferente de ensinar a teoria, onde os alunos possam despertar o interesse e uma participação ativa na construção do seu conhecimento e do próprio desenvolvimento cognitivo, permitindo relacionar a teoria com a prática.

Portanto, o objetivo desse trabalho é investigar as contribuições do uso do objeto digital de aprendizagem "Futsal RIVED" em aulas de Educação Física para alunos do $4^{\circ}$ ano do ensino fundamental da Escola Municipal Coração de Jesus do Município de Segredo, Rio Grande do Sul, Brasil.

\section{MATERIAL E MÉTODOS}

O trabalho foi desenvolvido na Escola Municipal de Ensino Fundamental Coração de Jesus, localizada no Município de Segredo, Rio Grande do Sul, Brasil.

A escola tem objetivo de proporcionar aos estudantes situações que contribuam para o desenvolvimento social, cognitivo, afetivo, psicomotor, atenção e o raciocínio lógico, dentro de uma pedagogia lúdica e de livre expressão, levando-as à estruturação das noções básicas na formação da sua 
personalidade e de caráter capazes de auxiliá-las na leitura e na escrita do mundo.

A escola possui um laboratório de informática, com 6 computadores, mas queencontram-se indisponíveis por falta de energia suficiente à rede. Para a aplicação do ODA foram usados somente dois computadores.

Quanto ao tipo de pesquisa, ela pode ser compreendida como um estudo dentro da modalidade de uma pesquisa-ação.

O público alvo do estudo foi a turma do $4^{\circ}$ ano da escola, composta por sete alunos. O instrumento de pesquisa utilizado foi um objeto digital de aprendizagem, "Futsal RIVED", encontrado no site http://portaldoprofessor.mec.gov.br/fichaTecnicahtml?id=25190.

O ODA "Futsal RIVED", foi escolhido pelo fato de o futsal ser um dos conteúdos a ser aplicado no trimestre final e estar bem presente na vida escolar e extraescolar do aluno. A aplicação do ODA deu-se no mês de setembro de 2012.

O Objeto Digital de Aprendizagem "Futsal RIVED", é disponibilizado pela Rede Interativa Virtual de Educação- RIVED, que é um programa da Secretaria de Educação à Distância-SEED que tem por objetivo a produção de conteúdos pedagógicos digitais, na forma de objetos digitais de aprendizagem.

O objeto digital de aprendizagem "Futsal RIVED" apresenta uma proposta pedagógica para o ensino dos fundamentos do futsal e propõe-se que através dele haja uma diversidade de vivências para que todos os alunos possam experimentar as amplas possibilidades da cultura corporal de movimento. ("Futsal RIVED- Guia do Professor")

Na figura 1 observa-se a tela inicial do ODA, que apresenta a possibilidade "carreira" e "treino", onde cada opção levará a um caminho diferente, porém com algumas semelhanças. Após visualizar as instruções do mascote, os alunos poderão escolher uma das opções, que deverá ser sugerida pelo professor, primeiramente, a opção "treino".

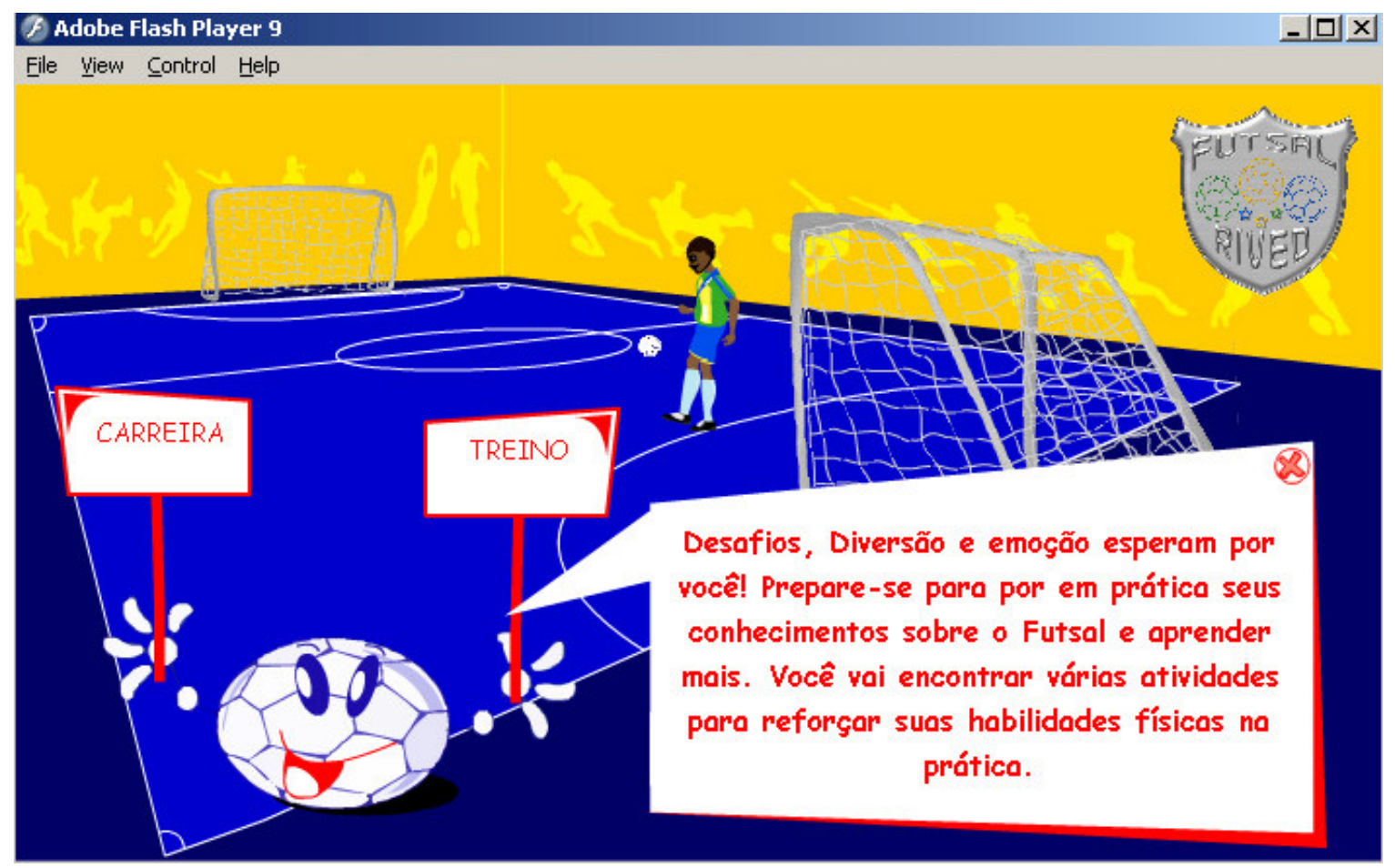

Figura 1: Tela inicial do ODA

Então irão visualizar a Tela de escolha do personagem, onde irão identificar o personagem escolhido dando-lhe um nome e um número.

Ao optar pela tela "treino", (figura 2), o usuário terá a chance de realizar cada fundamento escolhido quantas vezes quiser, identificando as movimentações de cada fundamento do futsal. 


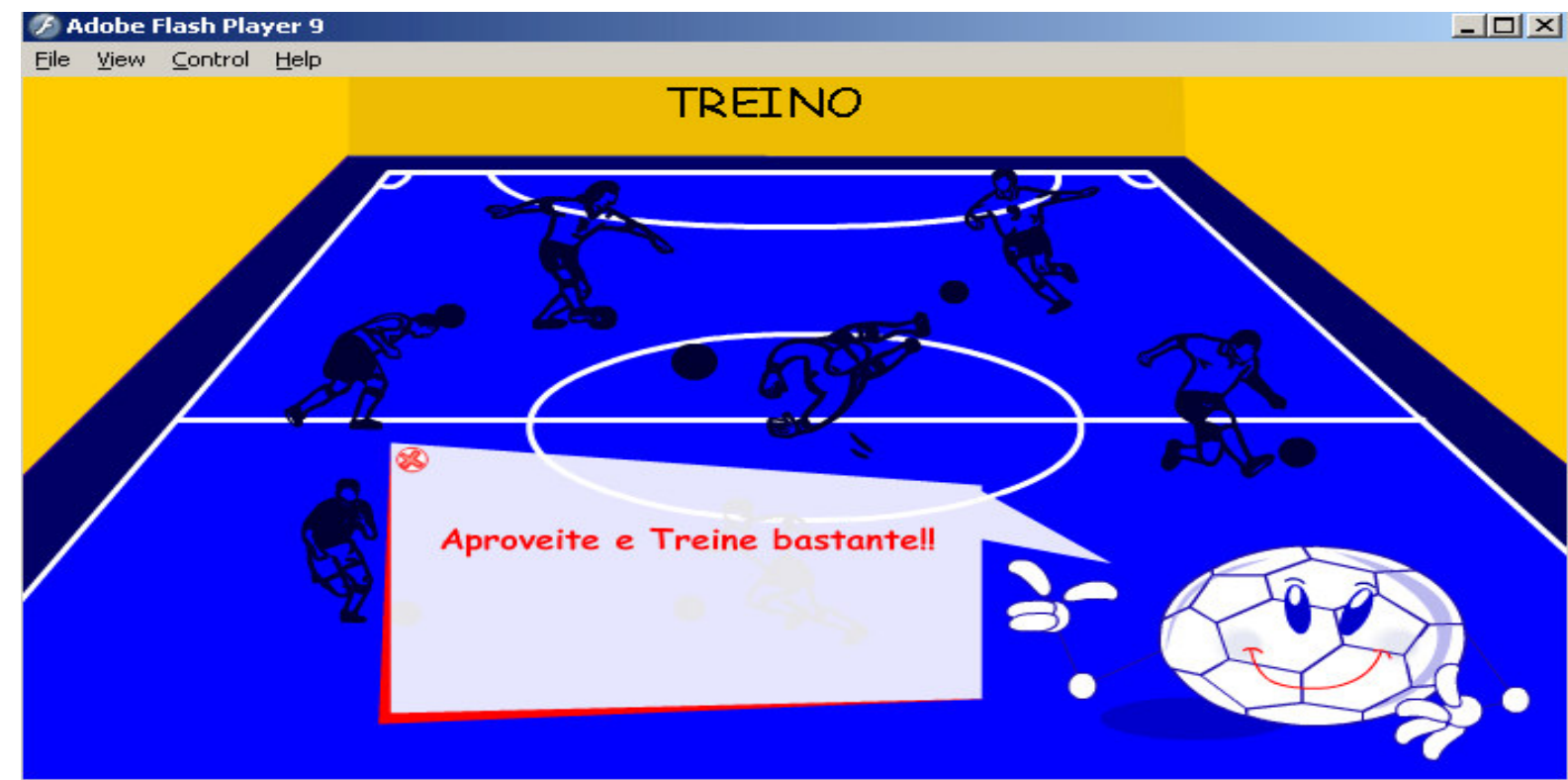

Figura 2: Tela treino

Ao optar pela tela "carreira", (figura 3), aparecerão as opções iniciante, intermediário e profissional, onde os alunos irão executar os fundamentos do futsal, reconhecendo as diferenças e dificuldades entre os níveis propostos.

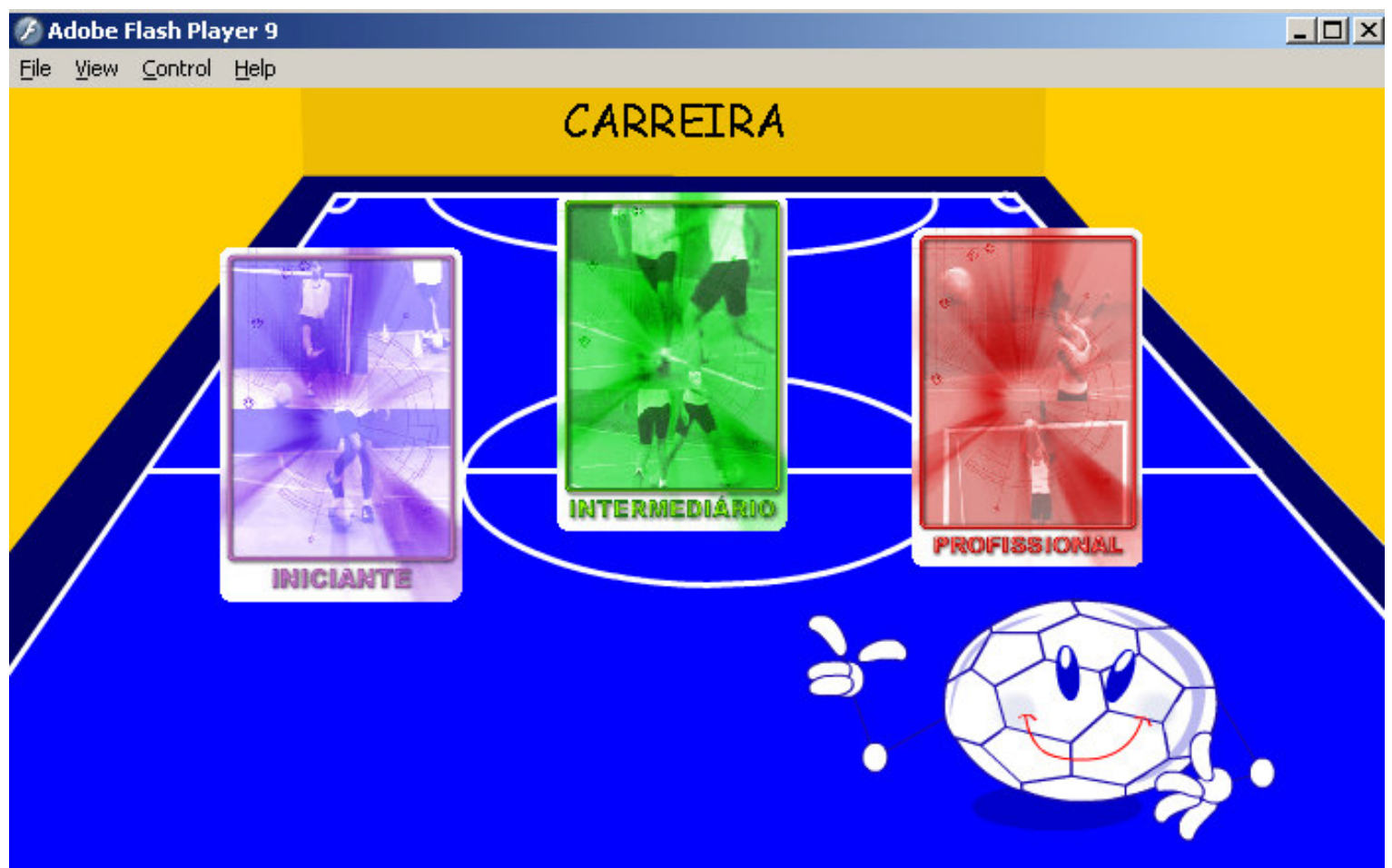

Figura 3: Tela carreira

$\mathrm{Na}$ opção iniciante os alunos podem identificar a movimentação executada nos fundamentos condução de bola, chute a gol e passe. Na opção intermediária, executarão os fundamentos de cabeceio e de drible. E na opção profissional, os fundamentos lançamento e técnica do goleiro.

Para apresentar o feedback da realização das atividades, aparecerá uma tela onde cada fundamento realizado aparecerá uma marcação "V" em verde. Caso não realize a atividade corretamente, aparecerá um "X" em vermelho. 

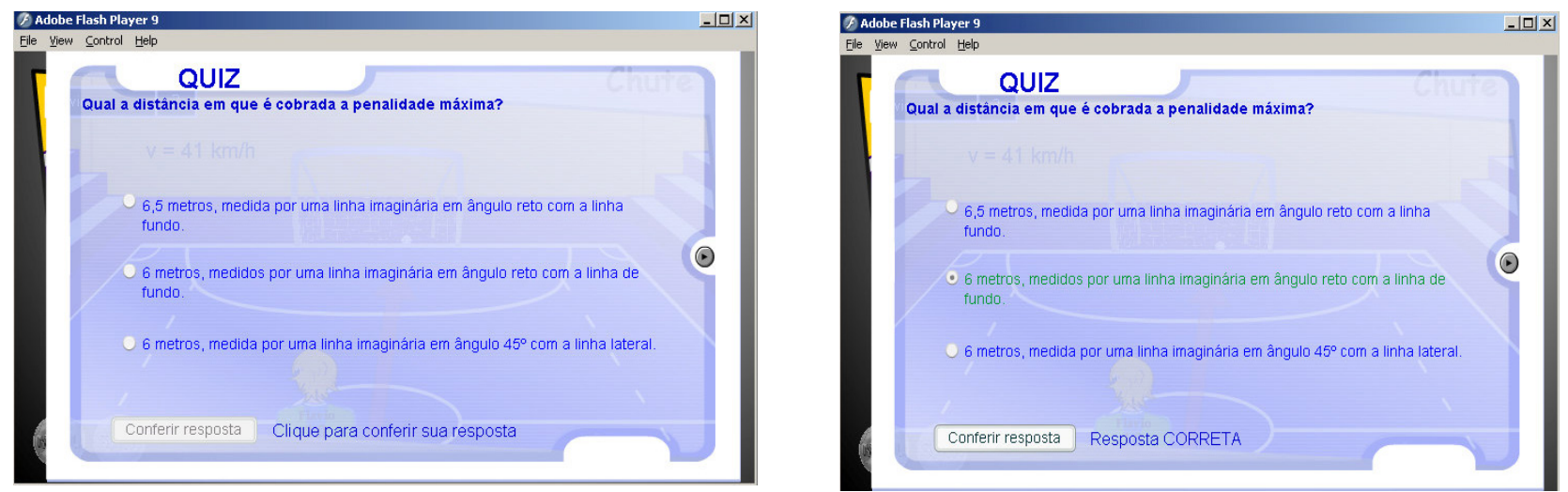

Figura 4: Tela do QUIS

Também na opção carreira, a cada fundamento realizado com sucesso surgirá a tela do QUIZ (figura 4), com questões referentes às regras do futsal. Após conferir a resposta escolhida, aparecerão em verde a opção certa e a informação se a resposta escolhida foi correta ou incorreta.

O ODA também nos proporciona uma tela com glossário, com o objetivo de reconhecer o significado das palavras utilizadas no jogo de futsal, uma tela de ajuda que vai orientar o usuário e a tela de dica, que orientará o usuário sobre conhecimentos acerca de cada fundamento.

Existe também uma tela com vídeos, onde poderão visualizar instruções dos movimentos a cerca do fundamento a ser trabalho em cada tela. A tela histórico, que possibilita ao professor uma avaliação do desempenho do aluno nas atividades propostas, além de proporcionar um meio de auto-avaliação para o aluno.

A cada opção de fundamento abrirá uma tela de jogo. Na tela (figura 5) observamos o fundamento condução de bola.

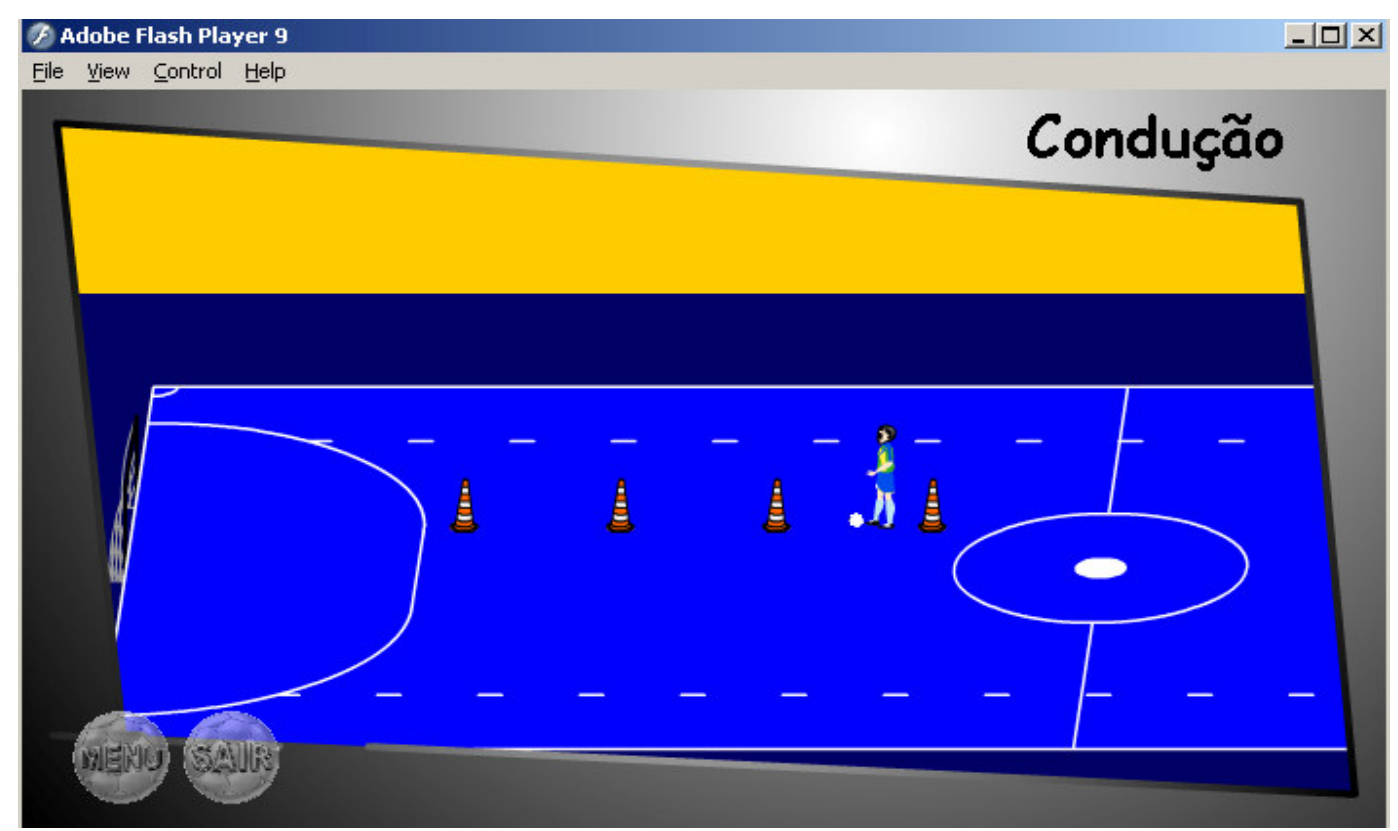

Figura 5: Tela de jogo: condução de bola

Nessas telas os alunos terão a oportunidade de executar cada fundamento, possibilitando a reflexão sobre cada um.

Ao final da execução da opção carreira aparecerá a tela final, com o personagem escolhido inicialmente, ilustrando a pontuação conquistada, proporcionando uma satisfação pessoal por ter alcançado o êxito nas atividades propostas.

Realizou-se a interatividade e exploração do ODA individualmente, onde usaram livremente a tecnologia, descobrindo, aprendendo e divertindo-se. Para isso foram disponibilizadas duas horas aulas. 
Após, a interação foi feita em grupo, analisando e discutindo os objetivos do objeto e sua exploração, onde os alunos foram conduzidos e orientados ocorrendo intervenções quando necessário. Foram usadas mais duas horas aulas para esta atividade.

Após a aula teórica, foi aplicado um questionário com questões fechadas e abertas (Quadro1) para investigar o perfil dos alunos e o uso do ODA (abordando de que forma esta tecnologia os ajudou na aprendizagem dos conceitos de cada um dos fundamentos do futsal, se gostaram ou não e quais dificuldades encontraram).

Quadro 1 - Questionário aplicado para estudantes sobre o uso do ODA.

\begin{tabular}{|c|c|}
\hline 1 & Qual sua idade? \\
\hline 2 & $\begin{array}{l}\text { Qual seu sexo? } \\
(\mathrm{)} \text { feminino }(\mathrm{)} \text { masculino }\end{array}$ \\
\hline 3 & $\begin{array}{l}\text { Você já repetiu alguma série? } \\
\left(\begin{array}{ll}() \operatorname{sim} \quad(\quad) \text { não } \quad \text { Em caso afirmativo. Em qual série? }\end{array}\right.\end{array}$ \\
\hline 4 & $\begin{array}{l}\text { Marque todos os recursos que você tem acesso em casa: } \\
\text { ( ) jornal impresso ( ) telefone celular ( ) telefone fixo } \\
\text { ( ) TV ( ) revistas ( ) rádio } \\
\text { ( ) computador de mesa ( ) computador portátil ( ) internet } \\
\text { ( ) antena parabólica ( ) aparelho de jogo }\end{array}$ \\
\hline 5 & $\begin{array}{l}\text { Você sabe utilizar o computador? } \\
\left(\begin{array}{l}\text { ( ) sim } \quad(\quad) \text { não } \\
\end{array}\right.\end{array}$ \\
\hline 6 & $\begin{array}{l}\text { Quais os recursos você mais gosta que a professora utilize em sala de aula? } \\
\text { ( ) quadro e giz ( ) livros ( ) revistas e jornais } \\
\text { ( ) mapas ( ) retroprojetor ( ) rádio } \\
\text { ( ) televisão ( ) computador ( ) jogos no computador } \\
\text { ( ) brincadeiras e jogos na quadra de esportes } \\
\text { ( ) outros }\end{array}$ \\
\hline 7 & $\begin{array}{l}\text { Você possui dificuldades para aprender as matérias que as professoras ensinam? } \\
\text { Por quê? }\end{array}$ \\
\hline 8 & $\begin{array}{l}\text { Você gostou do jogo de futsal no computador que a professora ensinou na aula? } \\
\text { Por quê? }\end{array}$ \\
\hline 9 & Teve alguma dificuldade para jogar? Por quê? \\
\hline 10 & $\begin{array}{l}\text { Você gostaria de ir ao laboratório de informática aprender os conteúdos? Fica mais } \\
\text { fácil de aprender? }\end{array}$ \\
\hline 11 & Como seria a escola que você gostaria de estudar? \\
\hline
\end{tabular}

Ainda, posteriormente, os alunos tiveram aulas práticas na quadra de esportes, sempre sendo retomados os conceitos relacionados aos fundamentos que foram vivenciados no objeto digital de aprendizagem. Para a prática foram necessárias quatro horas aulas. 


\section{ANÁLISE E DISCUSSÃO DOS RESULTADOS}

Conhecer o perfil e auxiliar a inclusão digital dos alunos das escolas públicas da zona rural é fundamental para o aprimoramento do processo de ensino-aprendizagem dos estudantes, uma vez que, a educação é um dos caminhos para desenvolvimento dessas comunidades.

Os alunos entrevistados, na Escola Municipal de Ensino Fundamental Coração de Jesus possuem idade entre $9(71 \%)$ a $10(29 \%)$ anos, sendo a maioria do sexo masculino (60\%) (Questão 1 e 2).

Cerca de $57 \%$ destes alunos já reprovaram na escola sendo que $100 \%$ destes reprovaram no $4^{\circ}$ ano, o que demonstra a dificuldade dos alunos no processo de ensino-aprendizagem (Questão 3). No Brasil, onde a exclusão escolar (evasão, repetência) é um elemento estruturante do sistema de ensino, redimensionar o pensar-fazer pedagógico, incorporando as TIC, pressupõe um passo no processo de socialização de um bem cultural e viabilização da educação que se faz necessária para uma sociedade em que o conhecimento ainda se limita drasticamente às minorias (SILVA 2007).

Neste sentido, promover a inclusão digital é algo que, além das questões sociais envolvidas, é um direito que o cidadão tem de participar das tecnologias existentes, ter uma educação mais atualizada, capacitação profissional, maior competitividade no mercado, etc (COSTA et al. 2007).Para Aquino (2008, p.97), "incluir é um dispositivo inteligente, a partir do qual os indivíduos de diferentes culturas e grupos sociais podem experimentar, reinventar e agir sobre a informação".

Assim, os recursos disponibilizados pelos objetos digitais de aprendizagem influenciam na motivação dos alunos e consequentemente na aprendizagem. Na ideia de Wallauer (2010) é evidente que esses objetos se propõem a auxiliar o aluno a compreender melhor o conteúdo trabalhado podendo se tornar uma ferramenta potencialmente significativa que vem a facilitar a aprendizagem.

A questão 4 visa diagnosticar quais os recursos tecnológicos os alunos possuem em suas residências. Dentre as alternativas disponibilizadas, verificou-se que todos os alunos possuem na sua residência aparelhos de televisão, rádio, antena parabólica, telefone celular, jornal, revistas e aparelhos de jogos, entretanto somente $30 \%$ possuem computador de mesa, mas todos sem acesso à internet.

Os alunos (100\%) relataram saber usar o computador para digitação de textos, pesquisas na internet, assistir vídeos, pintar, ouvir músicas e jogos, sendo estes realizados na escola pelos alunos que não possuem o computador em casa (Questão 5).

Esses resultados demonstram que mesmo em se tratando de uma zona rural a tecnologia está presente e desperta o interesse dos alunos, corroborando com Rosini (2007) que afirma que: essa nova cidadania da cultura informatizada requer novos hábitos intelectuais de simbolização, formalização do conhecimento, manuseio dos signos e das representações, o que também exige uma nova gestão social do conhecimento, apoiada num modelo digital explorado de forma interativa. Para esse autor, desprezar ou mesmo minimizar neste momento histórico a importância das tecnologias na educação presencial é errar de século, assim torna-se fundamental a fluência tecnológica do professor.

Sobre os recursos que os alunos mais gostam que a professora utilize em suas aulas, quadro 3 , $100 \%$ dos alunos citam o computador, o rádio, brincadeiras e jogos na quadra de esporte e a televisão, e cerca de $57 \%$ apontaram gostar também de livros, jornais e revistas e $28 \%$ gostam de mapas (Questão 6). Ressalta-se, que nenhum aluno (0\%) mencionou o quadro negro.

Esses resultados estão de acordo com Kenski, (2007), que afirma não haver dúvida de que as novas tecnologias de comunicação e informação trouxeram mudanças consideráveis e positivas para a educação, atraindo os alunos e facilitando o processo de ensino-aprendizagem. A autora ainda ressalta que vídeos, programas educativos na televisão e no computador, sites educacionais, softwares diferenciados transformam a realidade da aula tradicional, dinamizam o espaço de ensino-aprendizagem, onde, anteriormente, predominava o quadro negro, o giz, o livro e a voz do professor.

A questão 7 aborda as dificuldades no aprendizado, 100\% dos alunos relataram que só a possuem por falta de atenção, devido a aula ser desinteressante e monótona.

Esse resultado reafirma o pensamento de Kenski (2007), as novas tecnologias de comunicação, sobretudo a televisão e o computador, movimentaram a educação e provocaram novas mediações entre a abordagem do professor, a compreensão do aluno e o conteúdo veiculado. A imagem, o som e o movimento oferecem informações mais realistas em relação ao que esta sendo ensinado. Quando bem utilizadas, provocam a alteração dos comportamentos e maior aprofundamento do conteúdo estudado.

Sobre o objeto digital de aprendizagem aplicado, observamos no quadro 4, 100\% dos alunos gostaram pelo fato de ser sobre o futsal, que é um assunto do seu interesse e da sua realidade cotidiana 
(Questão 8). Conforme Bianche e Hammes (2007, apud RODRIGUES 2010, pg1) "devemos usar as tecnologias no sentido cultural, científico e tecnológico de modo que os alunos adquiram condições para enfrentar os problemas e buscar soluções para viver no mundo contemporâneo".

Paulo Freire (2001) acredita na educação que considere o estudante construtor do seu conhecimento ao invés de somente reproduzi-los ou memorizá-los, pois a construção do conhecimento não pode ser uma questão de transferência de saberes. Também afirma Moran (2000, pg1) "educar é transformar a vida em processos permanentes de aprendizagem [...] é ajudar a integrar todas as dimensões da vida que lhes permitem encontrar seus espaços pessoais, tanto no social como no profissional [...]".

Cerca de $70 \%$ dos alunos dizem que foi bom aprender regras e táticas de uma forma diferente, assim como 71\% também acharam divertido, interessante e desafiante (Questão 9). Como afirma Moran (2000, pg2) "a construção do conhecimento a partir do processamento multimídia, é mais livre, menos rígida, com maior abertura, passa pelo sensorial, emocional e racional".

Quando perguntado sobre as dificuldades encontradas no ODA, 86\% dos alunos tiveram dificuldade nos comandos somente 14\% não encontraram dificuldades. (Questão 10). Entretanto, durante a aplicação do objeto digital de aprendizagem observou-se que todos os alunos se interessaram pelo tema explorando no todo o objeto utilizado. No momento da escolha do personagem davam nome de jogadores famosos. Tentaram fazer o máximo para realizar acertos nos processos pedagógicos, respondendo às questões de regras propostas e assistindo aos vídeos.

Alguns alunos não se interessaram pela leitura dos textos de orientação sobre o futsal, mas no desenvolver da atividade sentiram a necessidade de lê-los para conseguir mudar o seu nível de jogo sem erros, pois foram orientados que só poderiam avançar os níveis quando tivessem todos os acertos. Assim, todos os alunos conseguiram chegar ao fim do objeto com êxito.

Sobre a aplicação na prática, mostraram-se empolgados e com maior interesse para fazer o que praticaram no computador igualmente na quadra de esportes, assim possuindo um melhor desempenho. Dessa forma, evidencia-se que diante da necessidade de serem diversificadas as possibilidades e formas de agir e aprender, as tecnologias de informação e comunicação (TIC) abrem oportunidades para a ação dos indivíduos e a diversificação e transformação nos ambientes de aprendizagem (MARTINSI, 2008).

Segundo Nascimento (2007), os ODA possuem como característica fazer com que "a aprendizagem se torne mais efetiva e mais profunda que a obtida pelos meios tradicionais".

Ainda, (KENSKI, 1996, p.146) relata que ao se trabalhar, adequadamente, com essas tecnologias, constata-se que a aprendizagem pode se dar com o envolvimento integral do indivíduo, isto é, do emocional, do racional, do seu imaginário, do intuitivo, do sensorial em interação, a partir de desafios, da exploração de possibilidades, do assumir de responsabilidades, do criar e do refletir juntos.

$\mathrm{Na}$ questão sobre aprender através da mediação do computador, 100\% dizem que é mais interessante, divertido, diferente e que aprendem com mais entusiasmo, compreendendo com mais facilidade o conteúdo e permitindo que eles sejam sujeitos da construção dos seus conhecimentos (Questão 11). Freire (2001) defende uma educação dialógico problematizadora, que nega o ato de transferir, narrar ou transmitir conhecimentos aos pacientes educandos, pois uma educação problematizadora deve organizar-se em torno da visão do mundo dos educandos e urge trabalhar esses conteúdos, não como pacote que se entrega aos estudantes, mas como atividade deliberada, que busca soluções para problemas contextualizados e relevantes na vida dos educandos.

Os resultados corroboram com Valente $(1998$, p.30), que menciona que o computador pode enriquecer ambientes de aprendizagem, onde o aluno, interagindo com os objetos desse ambiente, tem chance de construir seu conhecimento, neste caso, o conhecimento não é passado para o aluno, o aluno não é mais instruído, ensinado, mas é construtor de seu próprio conhecimento.

Segundo Tavares (2006) a utilização dos ODA enquanto recurso pedagógico propicia uma participação ativa do aprendiz na construção do conhecimento e do seu próprio desenvolvimento cognitivo. Diz que os ODA se configuram como organizadores prévios, "como uma ponte cognitiva, facilitando a aprendizagem mais específica que se inicia com um entendimento consistente dos conceitos mais inclusivos do tema considerado".

Assim, acredita-se que os conteúdos vinculados à disciplina de Educação Física tornaram-se mais atraente, interessante e instigante, possibilitando um conhecimento mais concreto e uma aprendizagem mais dinâmica.

Em relação à Educação Física, Sebriam (2009, p.24) destaca que:

o fato da Educação Física se tratar de uma disciplina que possui uma práxis sumariamente 
prático-teórica, consideramos que as recentes e aceleradas transformações das condições de aprendizagem, com destaque para o desenvolvimento das TIC, as quais vieram trazer um novo ânimo a sala de aula, dinamizando e apoiando novas formas de ensinar e aprender, fácil será perceber que é necessário conferir atenção especial para que o ensino da Educação Física escolar se realize com maior sucesso de modo a favorecerem-se aprendizagens ativas, significativas, integradas e socializadoras.

Sobre a escola dos sonhos, $100 \%$ dos alunos gostariam de ter um computador por aluno e um ginásio de esportes, também comentaram sobre um refeitório, $71 \%$ gostariam que existisse na escola uma quadra de areia e 56,8\% gostariam de ter uma piscina e um refeitório (Questão 11).

\section{CONCLUSÃO}

Através desta pesquisa conclui-se que o uso das TIC, em específico do objeto digital de aprendizagem "Futsal RIVED", os alunos identificam e reconhecem com mais facilidade os fundamentos do futsal e compreendem melhor a sua execução. Com isso a aprendizagem torna-se dinâmica e eficiente, e há um maior entusiasmo e interesse tanto nas aulas teóricas quanto práticas.

Através desta metodologia os alunos mostraram-se motivados, pois tiveram uma aprendizagem diferenciada, de maneira lúdica e divertida, compreendendo melhor o conteúdo e consequentemente com um melhor desempenho em quadra. Assimilam melhor as regras, relacionando a teoria com a prática, tornando o conteúdo mais atrativo, vivenciando novas experiências e aprendendo com mais satisfação.

As dificuldades encontradas são somente pelo fato de os alunos não terem acesso ao computador em casa, somente na escola, por isso, possuem pouca prática do uso de teclado e do mouse, mas percebe-se que não ter acesso às tecnologias em casa não impede seu aprendizado através destas na escola.

Conclui-se, então, que as tecnologias aplicadas na educação como recursos pedagógicos adquirem função de auxiliar no processo ensino-aprendizagem, trazendo novos olhares e maneiras diferentes de aprender, mas que também é importante trabalhar assuntos de interesse e que fazem parte da realidade dos alunos. Que na maioria das vezes a aprendizagem fica prejudicada pelo fato de terem aulas desinteressantes e sem motivação.

\section{REFERÊNCIAS}

ALMEIDA, M. E. B.; PRADO, M. E. B. B. (2009). Integração tecnológica, linguagem e representação. Disponível em: http://midiasnaeducacao-joanirse.blogspot.com.br/2009/02/integracao-tecnologica-linguagem-e. $\underline{h t m l}$ Acesso: out/2012.

AQUINO, M.A. O Novo Status da Informação e do Conhecimento na Cultura Digital. Informação \& Sociedade: Estudos, João Pessoa, v. 18, n 1, p. 70-100, jan/abr 2008.

AUDINO, D. F.; NASCIMENTO, R. S. Objetosde Aprendizagem: Diálogos entre Conceitos e uma Nova Proposição Aplicada à Educação. Revista Contemporânea de Educação, vol. 5, nº 10, jul/dez, p.128-148, 2010. Disponível em: http://www.revistacontemporanea.fe.ufrj.br/index.php/contemporanea/article/ view/122/113Acesso: out/2012.

BARROS, D.M.V.B. Guia Didático sobre as Tecnologias da Comunicação e Informação: Material para o Trabalho Educativo na Formação Docente. Rio de Janeiro: Vieira \& Lente, 2009. 160p.

COSTA, L.; LEMOS, A. Um modelo de inclusão digital: o caso da cidade de Salvador.

DEMO, P. TICs e Educação. 2007. Disponível emhttp://pedrodemo.sites.uol.com.br/textos/tics.html Acesso: out/2012.

FREIRE, P. (2006). Pedagogia do Oprimido. São Paulo: Paz e Terra. 
FREIRE. P. Pedagogia do Oprimido.17.ed. Rio de Janeiro: Paz e Terra, 2001.

GIL, A. C. (2002). Como Elaborar Projetos de Pesquisa. 4. ed. São Paulo. Atlas.

GUILHERMO, O. E.P. TAROUCO, L. M. R.; ENDRES, L. A. M. Desenvolvimento de Objetos Educacionais: experimentos em hidráulica. Revista Renote: Novas Tecnologias na Educação, v.3, n², 2005. Disponível em: http://seer.ufrgs.br/renote/search/titles?searchPage=6Acesso: out/2012.

KENSKI, V. M. O Ensino e os resursos didáticos em uma sociedade cheia detecnologias. In VEIGA, Ilma P. Alencastro (org). Didática: o Ensino e suas relações. Campinas,SP, Papirus, 1996.

KENSKI. V. M. Educação e tecnologias: o novo ritmo da informação. Campinas, SP. Papirus, 2007.

MARTINSI, M.C. (2008). Situando o Uso da Mídia em Contextos Educacionais. Disponível em: http:// midiasnaeducacao-joanirse.blogspot.com.br/2008/12/situando-o-uso-da-mdia-em-contextos.html Acesso: out/2012.

MORAN, José Manuel; MASETTO, Marcos T.; BEHRENS, Marilda Aparecida. Novas tecnologias e mediação pedagógica.Campinas : Papirus, 2000.

RIVED, Rede Internacional Virtual de Educação. Futsal RIVED: Guia do Professor. Categoria: Educação Física Escolar $5^{\circ}$ a $8^{\circ}$ série, ensino fundamental. Subcategoria: Esporte Futsal. Disponível em: http:// objetoseducacionais2.mec.gov.br/bitstream/handle/mec/12469/GUIA\%20DO\%20PROFESSOR Futsal. pdf?sequence=9Acesso: out $/ 2012$.

RODRIGUES, R. B. TICs na Educação Física Escolar: é preciso saber utilizar. EFDesportes.com, Revista Digital. Buenos Aires, ano 15, n 147, agosto, 2010. Disponível em: http://www.efdeportes.com/efd147/tics-na-educacao-fisica-escolar.htm Acesso: out/2012.

ROSINI, A. M. (2007). As Novas Tecnologias da Informação e a Educação à Distância. São Paulo: Cengage Learning.

SEBRIAM, Débora C. da Silva. Utilização das Tecnologias da Informação e Comunicação no Ensino da Educação Física.Université de Poitiers Faculdade de Motricidade Humana de Lisboa Universidad Nacional de EducacióndeMadrid. Madrid: 2009 (Dissertação de Mestrado).

SILVA, M.N.S. Formação do Professor, Pedagogia de Projetos e as Tecnologias da Informação e Comunicação. Práxis Educacional, vol. 3, n. 3, 2007. Disponível em: http://periodicos.uesb.br/index.php/praxis/article/view/351 Acesso em: nov/2012.

TAJRA, S. F. Informática na Educação: novas ferramentas pedagógicas para oprofessor da atualidade. $3^{\mathrm{a}}$ ed. São Paulo, SP: Érica, 2001. p.84.

TAVARES, Romero. Objetos de Aprendizagem. Educação $360^{\circ}$. Entrevista concedida a Conexão Professor, Rio de Janeiro, 2006. Disponível em: http://www.conexaoprofessor.rj.gov.br/entrevista 03.aspAcesso: out/2012.

VALENTE, J. A. O computador na sociedade do conhecimento. Campinas: Unicamp/NIED, 1998.

WALlAUER, C. Z. P. Objetos de Aprendizagem como Apoio ao Processo de Alfabetização. UFSM, 2010. 